\title{
There Will Be a "Surgeromics" In Our Future? Where the Relationship between Technological Innovation and Knowledge and Surgery is Leading Us
}

\author{
Michele Rubbini* \\ Department of Surgery, Director Programma of Coloproctological Surgery, University of Ferrara, Italy
}

*Corresponding author: Michele Rubbini, Int'al Fellow ASCRS, Associated Professor of Surgery, Dept. of Surgery, Director Programma of Coloproctological Surgery, AUSL di Ferrara, Via Cassoli ,3044121 - Ferrara, Italy, Tel: +390532235669/

Fax.+390532235776; E-mail: rbb@unife.it

\begin{abstract}
Technological innovation and evolution of knowledge have always conditioned surgery both in technique and in the indications: it has resulted in a general greater well-being for patients. What will be the role of surgery in the future is currently under discussion. Here we show that SNPs genotyping leads the path towards personalized medical therapies. In the future it is therefore conceivable that genomics may lead the full personalized treatment plan. So, the need for surgery will depend upon the relationship between the individual genotype and a constellation of factors, able to influence the effectiveness of surgery. Finally, we introduce a new "omics" able to characterize the future of surgery: "Surgeromics", a neologism binding surgery to its individual determinants.
\end{abstract}

Received Date: December 18, 2015

Accepted Date: March 14, 2016

Published Date: March 18, 2016

Citation: Rubbini, M., et al. There Will Be a "Surgeromics" In Our Future? Where the Relationship between Technological Innovation and Knowledge and Surgery is Leading Us. (2016) J Gastro Dis Liver Func 2(2): 68- 72.

DOI: $10.15436 / 2471-0601.16 .724$

\section{Introduction}

Technological innovation and evolution of knowledge have always conditioned Surgery both in technique and in the indications. The Surgery of 1800 and of the first half of the 1900 was affected by problems mainly due to the spread of infections, pain control and the effectiveness of anesthetic techniques: problems solved with the findings on antibiotics, analgesics, use of anesthetic gases. At the end of the Second World War, both the European and Americans Schools of Surgery were still marked on the assumption that the Oncological Surgery, had to be based on the greater removal of diseased tissue as possible as represented the main therapeutic tool against the majority of solid tumors, Over the years, due to the continuous thrust of technological innovation we moved to a new vision of the role of Surgery : a part of an integrated therapeutical plan where the synergies between clinical and laboratory activities are the conceptual basis of a new personalized therapy. Indeed new techniques and procedures tend to reduce as much as possible the demolitive surgical phase, side effects, or the consequent physical mutilation, and held in more and more attention to the characteristics of the individuals, their expectations and overall well-being, so ensuring the best possible therapeutic efficacy (Table 1) 
Table 1: Relationship between innovation and effect on surgery in the second half of last century

\begin{tabular}{|l|l|l|l|}
\hline FROM & INNOVATION & FIELD OF APPLICATION & EFFECT ON SURGERY \\
\hline $1960-70$ & $\begin{array}{l}\text { TECHNOLOGY EQUIPMENT AND } \\
\text { MATERIALS }\end{array}$ & Interventional Endoscopy & $\begin{array}{l}\text { Reduction in open surgery indications, Biliary } \\
\text { Tract, Urinary Tract, Prostate }\end{array}$ \\
\hline $1970-80$ & $\begin{array}{l}\text { TECHNOLOGY EQUIPMENT AND } \\
\text { MATERIALS }\end{array}$ & Staplers & $\begin{array}{l}\text { Reduction in invasiveness Abdominal and } \\
\text { Thoracic Surgery }\end{array}$ \\
\hline & PARTICLE PHYSICS & Nuclear Medicine, Radioisotopes & Reduction in invasiveness Brest Surgery \\
\hline $1980-90$ & $\begin{array}{l}\text { TECHNOLOGY EQUIPMENT AND } \\
\text { MATERIALS }\end{array}$ & Laparoscopic Surgery & Reducrion indications in Gastro-duodenal Surgery \\
\hline $1990-00$ & $\begin{array}{l}\text { TECHNOLOGY EQUIPMENT AND } \\
\text { MATERIALS ELECTRONICS }\end{array}$ & Robotics Prosthetics Materials & $\begin{array}{l}\text { Reduction in invasiveness and } \\
\text { Infectious complications }\end{array}$ \\
\hline $2000-10$ & $\begin{array}{l}\text { TECHNOLOGY EQUIPMENT AND } \\
\text { MATERIALS }\end{array}$ & $\begin{array}{l}\text { Nanotechnologies Molecular } \\
\text { Medicine Genetics and "Omics" }\end{array}$ & $\begin{array}{l}\text { Reductions in indications and invasiveness in } \\
\text { General Surgery Nanosurgery }\end{array}$ \\
\hline FUTURE & $\begin{array}{l}\text { ALL PREVIOUS AND MORE IN } \\
\text { GENETICS }\end{array}$ & $\begin{array}{l}\text { Personalized Genomics Medicine } \\
\text { and Surgery Decision Making } \\
\text { Process }\end{array}$ & $\begin{array}{l}\text { Surgeomics ? The use of surgery will depend on } \\
\text { the individual genetic characteristics and the } \\
\text { complex of therapeutic possibilities }\end{array}$ \\
\hline
\end{tabular}

Periods expressed in Decades in which startred the clinical practice induced by related innovation and consequential effect on Surgery. Innovations of each decade added to the previous realize an overall reduction in number of surgical procedures intended as indications to open surgery, degree of invasiveness measurable as reduction in length of hospytal stay, after surgery complications and side effects or socially disabling mutilations.

This has resulted in better overall health outcomes due to shorter hospital stays, less pain, less scarring, faster recovery times, fewer complications and an increase in demand of minimally invasive techniques and has also greatly contributed to the reorganization of health facilities, and to reset the processes of patient managing and of therapeutic decision making. Furthermore, they have helped to overcome the believe that the greater the demolition the greater therapeutic efficacy could be introducing the concept that surgery is part of a more general treatment plan.

In the last decade, the technological evolution of nanotechnology, molecular medicine and genetics has greatly contributed to a further development of the diagnosis and treatment of cancer, opening the way for intervention increasingly targeted to the characteristics of the patient. (Table 2). The result of these technological innovations, has increased our diagnostic and therapeutic options, and the combination of various Single Nucleotide Polymorphisms and/or presence of some Signalling Pathways, have been linked both to the risk of cancer and the efficacy of chemotherapy so giving a strong impulse to setting of personalized therapies. Thus, just as today the SNPs genotyping leads the path towards personalized medical therapies ${ }^{[1]}$, in the near future it is conceivable that genomics may lead the full personalized treatment plan ${ }^{[2]}$ of which Surgery, is an important part. Therefore as innovation has always produced a substantial improvement in the therapeutic efficacy of surgical procedures and a repositioning of their role, combining them with technical progress and a significant decrease in negative side effects, what can be expect from the relationship between innovation and Surgery in the coming years in terms of further benefit to the patient, thecnical improvement and about its conceptual role? The hypothesis that is developed here regards these aspects and how the possible future relationship between genomics and the role of surgery. In doing this, the need for surgery will depend upon the complex of relationships which will be elapsing between the individual genotype and a constellation of factors, able to influence the timing, the indication, the amplitude, the technical procedures and the effectiveness of surgery, so introducing the term "surgeromics", a neologism which lexically binds surgery to its individual determinants.

Table 2: Relationship between innovation, correlation to cancer diagnosis, treatment or prognosis and clinical outcome in the last decade.

\begin{tabular}{|c|c|c|c|}
\hline Author & Innovation & Correlation to & Clical Outcome \\
\hline Hong et $\mathrm{al}^{[8]}$ & Genotyping & Diagnosis ,Therapy and prognosis & Personalized medicine \\
\hline Ginsburg et a ${ }^{[9]}$ & Genomic Medicine & $\begin{array}{l}\text { Identify individual risk Guide clinical } \\
\text { maangement }\end{array}$ & Health care decision making \\
\hline Simons et $\mathrm{al}^{[12]}$ & Genotyping & Risk of CRC & Possible modification of therapy response \\
\hline Billeter et al ${ }^{[10]}$ & MicroRNA & $\begin{array}{l}\text { More aggressive tumor biology Invasiveness } \\
\text { Formation of Metastasis Local recurrence }\end{array}$ & Possible suppression of tumor progression \\
\hline Li et al ${ }^{[11]}$ & MicroRNA 215 & Relapse of operated CRC & $\begin{array}{l}\text { Potential predictive marker of relapse after radical } \\
\text { suergery for CRC }\end{array}$ \\
\hline Chae et al. ${ }^{[23]}$ & MicroRNA 367 & Prognosis of CRC & $\begin{array}{l}\text { Potential marker for prognosis after surgery for cu- } \\
\text { rative CRC }\end{array}$ \\
\hline Blanco et al ${ }^{[3]}$ & Nanotechnology & Chemotherapy & Improved antitumoral efficacy \\
\hline Weldon et al ${ }^{[4]}$ & Nanomedicine & Surgical procedures & Potential to affect the field \\
\hline Allhoff $\mathrm{F}^{[5]}$ & Nanomedicine & Surgical treatment Philosophycal aspect & Conditioning surgical procedures and thecniques \\
\hline
\end{tabular}

The role of surgery in the treatment plan has to be considered in the context of the personal characteristics of the patient opening the way for a real future personalized treatment. 


\section{The "OMICS"}

The further revolution of the new century in surgery relates to the use of nanotechnology ${ }^{[3-5]}$, molecular medicine and new knowledge about genomics: possibility to use molecules that bind selectively to tumor cells at the same time conveying the therapeutic agents (Theranostics) ${ }^{[6]}$, greater diagnostic efficacy especially at the level of molecular biomarkers, identification of genotypic characteristics, the role of "omics" and polymorphisms associated with disease development or predictive of therapeutic efficacy, are now the elements that form the basis of modern medicine and surgery accordingly.

The suffix "omics" has no precise or unique meaning: in biology adding the suffix makes the meaning of the word dynamic, since it indicates not only the characteristics of the discipline but also the techniques, the set of functions, the relationships between them and with other internal and external environments and the changes that as a result of these interactions can be generated.

Especially in the last ten years, to the amount of information derived from studies of Nutrigenomics ${ }^{[7]}$, (the study of how specific genetic polymorphisms interact with the bioactive food components in conditioning the level of cancer risk related to the dietary habits), Transcriptomics, (the study of the RNA transcripts produced by the genome at any time and the changes under different circumstances due to different patterns of gene expression), Metabolomics, (the study of the metabolites and how they are affected by specific cellular processes), Proteomics ( the study of protein structure and function expressed by a genome ), in addition to those relating to the Pharmacogenomics ( the study of genetic variations that influence individual response to drugs) which has opened new horizons in research and therapy of cancer. Today we currently talk about individual risk, personalized medicine and/or thera$\mathrm{py}^{\left[{ }^{[8]}\right.}$ and individual response to pharmacological treatment, precisely in dependence on some of those characteristics defined by the "omics" that , as argued by Ginsburg and Willard (2009), - "DNA-based risk assessment for common complex disease, molecular signatures for cancer diagnosis and prognosis, and genome-guided therapy and dose selection are just among the few important examples for which genome information has already enabled personalized health care along the continuum from health to disease. In addition, information from individual genomes, which is a fast-moving area of technological development, is spawning a social and information revolution among consumers that will undoubtedly affect health care decision making". ${ }^{[9]}$-meaning that the whole treatment plan may have different outcomes depending on the personal characterization given by omics, abandoning the old concept of "one size fits all" in order to land a real personalized treatment plans. It is also possible that the treatment plan may depend on personal ability to respond to chemotherapy, to develop metastasis, be able to use predictive or prognostic markers of outcome of surgery ${ }^{[10-12]}$.

\section{A New "OMICS" in Our Future?}

The treatment plan for a cancer patient is currently the result of an interdisciplinary vision that takes place in a single path defined by the combined action of several therapeutic modalities: this type of behaviour is the result of new ways of diagnostic ability and therapeutic specificity. The use of nanotechnology, the possibilities arising from the knowledge in molecular medicine, pharmacogenomics and SNPs genotyping enable us to determine both the possibility and efficacy of treatments, lying the foundation of a personalized treatment. In this context, the knowledge of the genetic characteristics of a patient related to its diseases risk and to its chance to have benefit from chemotherapy or other targeted therapies allows us to draw up his own plan of both prevention and treatment.

Indeed the research conducted so far, evidence of a difference in risk of cancer depending on the presence of some SNPs: in particular, in the context of neoplastic disease of the Colon and Rectum in the last decade there have been important and significant developments that have led to the identification of several SNPs and Signaling Pathways whose activity is closely linked to the onset, development, progression and metastasis of cancer ${ }^{[13-14]}$, as they are understanding some of the features of therapeutic effectiveness depending on the presence or absence of particular SNPs or specific combined oncogenic pathways ${ }^{[15]}$ : to date, we can talk about of SNPs able to affect increase or decrease of the risk of getting cancer or the efficacy of specific pharmacological treatment ${ }^{[16-18]}$. Tremblay et al. refer that, currently,10\% of marketed medications propose or recommend genetic testing for optimal treatment ${ }^{[1]}$.

Thus, the SNPs genotyping become preliminary to setting personalized plan of prevention and treatment of neoplastic disease: this indeed, together with other individual characteristics, will determine both the suitability of preventive action in fields as lifestyles, diet ${ }^{[19]}$, environmental characteristics, and the individual treatment plan having made known the response to the use of chemotherapy, the prediction of metastasis or the effectiveness of surgery alone compared to the combination of surgery and chemotherapy or radiochemotherapy. Surgery, is posed, therefore, in a new position since the use of it will change in the timing, indications, amplitude of the demolition and prognostic expectations depending on the individual patient's compliance to all those factors, in turn, determined by its individual gene structure. Finally, performing surgery as the first or second instance may be decided on the basis of the individual capability to respond to drugs toxicity, to their metabolization or intracellular transport, e.g. This ultimately the result of the application to surgery of the progress of knowledge and innovation in this last decade.

So, will we have a future without surgery? Of course not. Probably with less surgery or with a different kind and role of surgery: over the World we are seeing a steady reduction in surgical admissions and to an improvement of minimally invasive techniques.

However it is feasible, that W Surgery, will become a not-of-first-instance-therapeutic-tool but conditional on nanotechnology, biomolecular and pharmacogenomical procedures ${ }^{[20]}$, determined and able to determinate aspects of genetic or related to it: here, borrowing the term "omics" from biology and transporting it in a clinical setting, we can define this with a neologism formed by the merger between "surgery" and "omics": the "Surgeromics".

"Surgeromics", is therefore the field that defines that specific set of individual characteristics and environmental conditions, lifestyles, habits, in which the use of surgical therapy is mediated by the characteristics of individual responsiveness of the patient 
to the various therapies which in turn can determine both the timing and the type of surgery in the context of a more comprehensive treatment plan.

\section{The Next Decade of Researches and Clinical Translational Application}

There are many topics and many levels on which to develop further research for testing the hypothesis considering that not a unique research but a whole body of research should aim to fully demonstrate the utility of genotyping as a basis for personalized medicine $^{[1]}$. In the next decade, the research should develop themes which can further define: a) susceptibility to cancer (SNPs association for colorectal cancer e.g.); b) the personal characteristics of useful use of chemotherapy; c) the personal characteristics of prognosis following surgery, and specifically:

Scentific Researches Themes: a) new associations between diseases and genes; b) interaction between polygenes and environmental factors; c) the combinations of SNPs that, in turn ,condition signaling pathways and transcription; d) genomic tools able to precise prediction and treatment of therapy; e) the role of diagnostic and prognostic evaluation of cancer patients of microRNAs.

Organization Patterns : to establish prophylactic paths for patients who show positive diagnosis for cancer susceptibility and /or a personalized therapeutic one that is affordable even to Public or Mixed Health System .To do that it is necessary to create projects involving the large-scale introduction of diagnostic and genotyping analisys whether they are established or new ${ }^{[21]}$ in order to increase efficiency, lowering costs and encourage the construction of models of personalized medicine and surgery as that reported by Brunicardi et al (2011) whose ultimate goal is summarized by the sentence: "the genomic profile guides choice of therapy"[22].

Laws and the Health Care System: on example of Genomics and Personalized Medicine Act of 2007 (US) have to be proposed and approved laws and decrees defining objectives, guidelines and funding, supporting new health strategies that recognize the value of personalized genomic medicine and redefine the areas in which Health in the coming years will develop.

Educational programs: The educational curricula in the Schools of Medicine should aim to increase the knowledge of both genomic and its interrelationships with diseases and awareness for the next generation of healthcare workers, surgeons included, that genetic information can be used to induce people to adopt behaviors and actions useful for the prevention and treatment of diseases

\section{Conclusion}

Much remains to be understood and defined, but the future is traced and moves towards a greater understanding of the individual genotype and its clinical applications. Surgeromics is a neologism, with which mean a field concerned with the use of surgery depending on the results of a new diagnostic and therapeutical pathway dictated both by the individual genotyping and the current availability of technologies, knowledge and diagnostics: : "genotipyng" will be the basis to identify susceptible individuals and personal responsiveness to therapy; "molecular medicine" the methodology through which to verify the presence of predictive biomarkers; "nanomedicine" and imaging applied to it, represent the way for treat and monitor the effectiveness of treatment. The results of the research conducted so far on the issue of "omics" indicate that cancer therapy is moving even more towards personalized formulas and even surgery, is moving to a new collocation in the context of a more general treatment plan, so taking part in a major new therapeutic revolution, in another step forward the clinical use of new technologies and becoming a new element of a new customized mode to address cancer prevention and therapy.

Conflicts of Interest: I have no conflict of interest.

Grants: I have no support in the form of grants or any other form. 


\begin{tabular}{|l|l|}
\hline \hline Exercutive Summary & \\
\hline Genotipyng & $\begin{array}{l}\text { These fields have to be investigated further: a) susceptibility to cancer ( SNPs association for colorectal cancer e.g.); } \\
\text { b) the personal characteristics of useful use of chemotherapy; c) identification and composition of groups at risk of } \\
\text { cancer. }\end{array}$ \\
\hline Molecular Medicine & $\begin{array}{l}\text { To verify the presence of predictive biomarkers. Expand clinical research on the role of Micro RNA and Signaling } \\
\text { pathways in order to identify predictive biomarkers of disease and their actual predictive reliability }\end{array}$ \\
\hline Nanomedicine & $\begin{array}{l}\text { To treat and monitor the effectiveness of therapy. Deeper search of new nano platforms for diagnosis and intracellular } \\
\text { pluritherapy Search imaging techniques are able to identify more precisely the diseased cells and their targets for the } \\
\text { treatment. }\end{array}$ \\
\hline Surgeromics & $\begin{array}{l}\text { Use of surgery depending on the results of a new diagnostic and therapeutical pathway dictated both by the individual } \\
\text { genotyping and the current availability of technologies. This will lead to further benefits for the patient and resource } \\
\text { savings for health systems }\end{array}$ \\
\hline Personalized & $\begin{array}{l}\text { Orient the medicine towards the creation of personalized pathways of treatment. To do that it is necessary to create } \\
\text { projects involving the large-scale introduction of diagnostic and genotyping analisys , in order to increase efficency, } \\
\text { lowering costs and encourage the construction of models of personalized medicine }\end{array}$ \\
\hline $\begin{array}{l}\text { Laws and Health } \\
\text { Care Systems }\end{array}$ & $\begin{array}{l}\text { Single national Health Systems have to be proposing and approving laws and decrees defining objectives, guidelines } \\
\text { and funding, supporting new health strategies that recognize the value of personalized genomic medicine and redefine } \\
\text { the areas in which Health in the coming years will develop. }\end{array}$ \\
\hline Education & $\begin{array}{l}\text { The educational curricula in the Schools of Medicine should aim to increase the knowledge of both genomic and its } \\
\text { interrelationships with diseases and awareness for the next generation of healthcare workers , surgeons included, as } \\
\text { this will lead to new benefits for patients and lower overall costs for governments }\end{array}$ \\
\hline
\end{tabular}

\section{References}

1) Tremblay, J., Hamet, P. Role of genomics on the path to personalized medicine. (2013) Metabolism 62(Suppl1): S2-S5.

2) Kalia, M. Personalized oncology: recent advance and future challenges. (2013) Metabolism 62(Suppl 1): S11-S14.

3) Blanco, E., Hsiao, A., Mann, A.P., et al. Nanomedicine in cancer therapy: innovative trends and prospects. (2011) Cancer Sci 102(7): 12471252 .

4) Weldon, C., Tian, B., Kohane, D.S. Nanotechnology for Surgeons. (2011) Wiley Interdiscip Rev Nanomed Nanobiotechnol 3(3): $223-228$.

5) Allhoff, F. The coming era of nanomedicine. (2009) Am J Bioeth 9(10): 3-11.

6) Kirui, D.K., Khalidov, I., Wang, Y., et al. Targeted near-IR hybrid magnetic nanoparticles for in vivo cancer therapy and imaging. (2013) Nanomedicine 9(5): 702-711.

7) Riscuta, G., Dumitrescu, R.G. Nutrigenomics: implications for breast and colon cancer prevention. (2012) Methods Mol Biol 863: $343-358$.

8) Hong, K.W., Oh, B. Overview of personalized medicine in the disease genomic era. (2010) BMB Rep 43(10): 643-648.

9) Ginsburg, G.S., Willard, H.F. Genomic and Personalized Medicine: foundations and applications. (2009) Transl Res 154(6): $277-287$.

10) Billeter, A.T., Druen, D., Kanaan, Z.M., et al. MicroRNAs. new helpers for surgeons? (2012) Surgery 151(1): 1-5.

11) Li, S., Gao, J., Gu, J., et al. MicroRNA-215 inhibits relapse of colorectal cancer patients following radical surgery. (2013) Med Oncol 30(2): 549.

12) Simons, C.C., Hughes, L.A., Smits, K.M., et al. A novel classification of colorectal tumors based on microsatellite instability, the CpG island methylator phenotype and chromosomal instability: implication for prognosis. (2013) Ann Oncol 24(8): 2048-2056.

13) The Cancer Genome Atlas Network: Comprehensive molecular characterization of human colon and rectal cancer. (2012) Nature 487(7407): 330-337.

14) Pasche, B., Wisinski, K.B., Sadim, M., et al. Constitutively decreased TGFBR1 allelic expression is a common finding in colorectal cancer and is associated with three TGFBR1 SNP's. (2010) J Exp Clin Cancer Res 29: 57.

15) Slattery, M.L., Lundgreen, L., Wolf, R.K., et al. Genetic Variation in the Transforming Growth Factor- $\beta$ - Signaling Pathway, Lifestyle Factors an Risk of Colon or Rectal Cancer. (2012) Dis Colon Rectum 55(5): 532-540.

16) Liao, X., Lochhead, P., Nishihara, R., et al. Aspirin Use, Tumor PIK3CA mutation and Colorectal-Cancer Survival. (2012) N Engl J Med 367: $1596-1606$.

17) Tian, S., Simon, I., Moreno, V., et al. A combined oncogenic pathway signature of BRAF, KRAS and PI3KCA mutation improves colorectal cancer classification and cetuximab treatment prediction. (2013) Gut 62(4): 540-549.

18) Lin, M., Gu, J., Eng, C., et al. Genetic polymorphisms in MicroRNA-related genes predictors of clinical outcomes in colorectal adenocaercinomas patients. (2012) Clin Cancer Res 18(14): 3982-3991.

19) Ross, S.A. Evidence for the relationship between diet and cancer. (2010) Exp Oncol 32(3): 137-142.

20) Ziogas, D., Roukos, D.H. Genetics and personal genomics for personalized breast cancer surgery: progress and challenges in research and clinical practice. (2009) Ann Surg Oncol 16(7): 1771-1778.

21) Roukos, D.H. Novel clinico-genome network modelling for revolutionizing genotype-phenotype-based personalizad cancer care. (2010) Expert Rev Mol Diagn 10(1): 33-48.

22) Brunicardi, F.C., Gibbs, R.A., Wheeler, D.A., et al. Overview of the Devolepment of Personalized Medicine and Surgery. (2011) World J Surg 35(8): 1693-1699.

23) Chae, Y.S., Kim, J.G., Kang, B.W., et al. Functional polymorphism in the MicroRNA-347 binding site as a prognostic factor for colonic cancer. (2013) Anticancer Res 33(2): 513-519.

Ommega Publishers

Journal Title: Journal of Gastrointestinal Disorder \& Liver Function (JGDLF)

Short name: J Gastro Dis Liver Func
ISSN No: 2471-0601

E-Mail Id: gastrology@ommegaonline.com

Website: www.ommegaonline.org 